\title{
The Sustainability and Applicability of Ancient Inca Water Engineering to Modern Day Society
}

\author{
Catherine Ruiz \\ The Academy for Science and Design \\ catherine.ruiz@asdnh.org \\ DOI: 10.29322/IJSRP.11.08.2021.p11675 \\ http://dx.doi.org/10.29322/IJSRP.11.08.2021.p11675
}

\begin{abstract}
Current water distribution systems are not very sustainable, including a lack of maintenance, the lack of attention to stormwater and runoff, and inadequate purification methods. However, the Inca engineers of the 11th century were able to keep water clean and reduce waste with limited resources. Part of this had to do with their focus on and their need to work with nature instead of against it when designing and constructing. This is something that is often overlooked today, where many times designers aim for the cheapest and simplest solution instead of the most sustainable, environmentally-friendly, and safest. This paper presents research on issues with current water engineering practices as well as potential solutions through ancient engineering.
\end{abstract}

Index Terms- Inca Water Engineering Sustainability Stormwater Drainage

\section{INTRODUCTION}

A ccess to potable water in adequate quantities is a basic human right, as it is crucial to survival. However, it is a commodity which is often taken for granted by its users and its regulators. Regardless of the economic and social differences between underdeveloped and developed countries, water is not always distributed or handled in a safe, clean, aware, and efficient manner, if even distributed at all (Puttaswamaiah, 2005). Disease, sewage, and other water pollutants constantly pose an ongoing threat to global populations as a result of the current state of modern infrastructure and the lack of planning for maintaining a sustainable approach to the distribution of water resources. Diseases caused by unsafe water constrain human resource development and productivity, sewage and stormwater and testing for pollution is insufficient. Many of the proposed solutions, such as more consistent maintenance and monitoring of water's travels, are expensive, time-consuming, or difficult to achieve. Time, attention, and awareness are three crucial requirements to maintain sustainability (Mays, 2011).

\section{LiterATURE REVIEW}

a. Defining Sustainability and Where it Sits Today

Water sustainability is one of the main topics of Larry Mays' Water Resources Engineering. Mays states that water used in proper amounts with the right quality for the needs of both humans and ecosystems is sustainable (Mays, 2011). The longevity of the environment and organisms that quality water serves is essential for defining sustainability targets. As outlined in Drinking Water Supply, which agrees with Mays'definition, sustainability has many demands and factors that authorities must contemplate and fully address (Puttaswamaiah, 2005). On the supply side of these necessary considerations, crucial aspects include the practicality of the reuse of water sources, including rainfall, surface flows, groundwater availability and recharge, surface runoff, and watershed in general, “...quality of available water, kinds of institutions and establishments, and operation and maintenance of water supply schemes" (Puttaswamaiah, 2005, p. 6). On the other hand, "population pressure, use and discharge of water by industries, inefficient land use, wastewater, fertilizer and pesticide flow into water bodies and soils, inappropriate water pricing mechanisms, etc." (Puttaswamaiah, 2005, p. 6) are the demand factors knowledge of which true sustainability requires. Puttaswamaiah highlights more specifically why these details are important by mentioning how carelessness leads to blockages in sewer systems or spreads of sanitary waste on surfaces that can increase pollution of resources like soil, water, and air, making the environment difficult to clean and maintain for the future.

A consistency among water sustainability research is the belief that system monitoring and organization are vital to ensuring the survival of water access when it comes to water management (Mays, 2011; Puttaswamaiah, 2005; Center for Sustainable Systems, 2020). This means that enduring water systems, management, quality, and monitoring are all large contributors to determining the longevity of sustainable efforts. To regulate, control, and execute these labors and goals, there are qualitative and quantitative standards that need to be set on both a community and authority level. 


\section{b. Modern Day Water Infrastructure and Management}

In Karnataka, India, the Rural Development and Panchayat Raj Department (RDPR) ensures the access of water in rural regions. This institution comprises many lower-level institutions for planning, implementing, and monitoring water systems and keeping track of maintenance (Puttaswamaiah, 2005). In addition to the RDPR and its sub-institutions, other institutions also work with water, such as the Groundwater Division of the Department of Mines and Geology. This establishment assesses groundwater resources, monitors the groundwater levels and quality, determines aquifer characteristics, selects sites and construction of artificial recharge structures, selects suitable sites for drilling bore wells, issues feasibility reports/certificates, and oversees the development of groundwater resources (Puttaswamaiah, 2005). The Health and Family Welfare Department conducts water quality testing for bacteriological contamination in different districts and the Directorate of Watershed Development recharges groundwater and works on soil conservation. The Karnataka Urban Water Supply and Drainage Board (KUWS\&DB) “...executes water supply and drainage schemes and transfers it to local bodies for operation and maintenance by providing technical guidance" (Puttaswamaiah, 2005, p. 20) and the Slum Clearance Board enables “...the slum dwellers to live in hygienic condition by providing basic amenities like drinking water, roads, drains, community bathrooms, stormwater drains, street lights, etc." (Puttaswamaiah, 2005, p. 21). These institutions are solid examples of the modern-day efforts of taking care of local and large-scale water problems.

Canada follows a six-stage process for water extraction, treatment, and distribution for its general use: (1) machines extract the water from underground aquifers or rivers and lakes for municipal water systems, brought up from wells, or delivered by trucks into holding tanks, (2) the water undergoes filtration and disinfection treatment, (3) the water goes through the set distribution systems, (4) wastewater collection systems are put into use, (5) wastewater undergoes treatment, and (6) the collection of stormwater, which consists of rain or melting snow (British Columbia Water \& Waste Association). The sixth step is not a part of this "cycle" but a necessary sidestep that includes both the collection of stormwater in storm drains and the process of releasing it back into lakes, rivers, and the ocean. Stormwater commonly picks up contaminants as it travels and nothing cleans it before it goes back into the environment, which can have harmful effects. Aside from this, water is regularly tested for quality in Canada and the provinces establish regulations for water quality standards. The treatment involved in this process includes the removal of grit, settle and floating separation, removal of biomatter and dissolved matter, chemical treatment, and the final filtration. Interestingly, only $7 \%$ of the original amount of extracted water makes it through all steps and tests for consumption (British Columbia Water \& Waste Association).

\section{c. The Issues With Today's Water Handling}

There are many severe disadvantages and shortfalls of the current infrastructure in regards to the safety of water itself and its effects on its surroundings all around the world. The ratio of irretrievable to retrievable runoff water has increased in recent years (Mays, 2011). Water-use flows accounting systems track "...water withdrawals for off-stream purposes, water deliveries at point of use or quantities released after use, consumptive use, conveyance loss, reclaimed wastewater, return flow, and instream flow" (Mays, 2011, p. 399). Mays says that the major types of problems for water resources projects include determining the optimal scale of the development project, the optimal dimensions of the various components of the project, and the determination of the optimal operation of the project (Mays, 2011). Sewer designs need to consider runoff predictions and rates, pipe sizing, extra intake, gravity flow, pipe shape, optimizing reduction of excessive deposition of solid material, and depth location for safety and access. Maximum and minimum flow velocities are important because of possible excessive erosion on sewer inverts.

Drinking Water Supply admits that Karnataka has no regular water system monitoring done after initial testing by the Rural Development Department and that there are no well-defined consequences of or mandates for it either (Puttaswamaiah, 2005). Karnataka also faces problems in institutional structure through a lack of integrated procedures for water quality testing and monitoring. Despite the four water quality testing institutions, there is no facility for testing for bacteriological contents and "...there is inadequate information or database on problems related to quantity of water supplied, water quality at source, distribution and consumer point, and information on health and environmental impacts" (Puttaswamaiah, 2005, p. 22).

Another pivotal circumstance incapacitates sustainability: urbanization. The large issues posed by megacities, including inadequate wastewater treatment and the handling of flooding, can be a major cause for the aforementioned problems (Puttaswamaiah, 2005). In Karnataka, less than a quarter of urban towns were found to satisfy the water adequacy norm, which shows gaps in engineering plans and capacity installation. Leakages and unaccounted for water disparity in distribution are results of lack of maintenance, especially in urban areas. The summer months in both rural and urban areas mean water scarcity due to dry conditions, evaporation, etc. The distribution network pipes also dry out as a result of the hot conditions and a lack of proper maintenance. These pipes, therefore, develop rust with their reduced water flow, further causing health and environmental problems attributable to the corrosion (Puttaswamaiah, 2005).

There are numerous reasons as to why the mishandling of stormwater is holding back sustainable efforts (Puttaswamaiah, 2005). Increased stormwater flow promotes the degradation of stream channels and promotes declines in water quality due to accumulated pollutants and erosion. It leads to increases in 
pollutant concentrations and flooding, groundwater recharge diminishes, and sewer overflows, which results in damage to aquatic life and the destruction of food sources and habitats. Many places ignore the conservation of stormwater, as well, which contributes to the above issues and does not help with any deficiencies.

There are issues similar to Karnataka in the United States, including mismanagement of water systems, as seen with the Flint, Michigan water crisis, and both regions have a focus on water quality standards (Puttaswamaiah, 2005; Center for Sustainable Systems, 2020). Large pieces of these problems in the United States are due to water consumption, as noted by the Center for Sustainable Systems (2020). Humans use water primarily for drinking, bathing, crop irrigation, industrial activity, and electricity generation, which has had a dramatic increase in recent years. Supplying the water for all of these needs while continuing maintenance and quality checks, using the correct treatments to deliver potable water, and optimizing the amount of water available becomes expensive. For example, each year, 240,000 main breaks occur out of the 2.2 million miles of distribution mains where the pipes typically last only 45 years (Center for Sustainable Systems, 2020).

While Water Resources Engineering and Drinking Water Supply do not call to attention the expenses of more sustainable water systems as much as the "U.S. Water Supply and Distribution Factsheet" does, all three sources emphasize the importance of thorough and consistent maintenance and quality testing (Mays, 2011; Puttaswamaiah, 2005; Center for Sustainable Systems, 2020). Taking into account all of the modern-day necessities and the costs to supply them is crucial when looking at sustainable options. There is a lot of indispensable planning and care that goes into water infrastructure, even if it is not enough yet, and this is where the aspirations of the Inca Empire begin to relate to the ambitions of modern-day society. The knowledge of the past could very well be the ticket to a better, more aware future.

\section{d. An Introduction to the Inca Empire}

In $1200 \mathrm{CE}$, the Inca Empire quickly became the largest in the Western Hemisphere and despite the lack of both modern technology and a written language, this society found innovative ways of working with nature to supply its needs through carefully crafted canals ("Sacred Roads"). The water systems of the Inca were efficient, hygienic, and environmentally sustainable even though they employed only basic knowledge and resources (Wright, 2010). Everything they created was thought-out and well-built as evident in their centuries-enduring structures. Global water issues may find solutions in the engineering principles and techniques of the Inca, including the use of layered terraces, the construction of surface-level and below-surface canal networks, and the attention paid towards the importance of runoff.

\section{e. Inca Water Engineering}

The Inca's respect for nature created a guide for their construction to work alongside nature instead of against it. This meant taking special care to avoid any environmental damage while constructing. Kenneth Wright, a civil engineer, says that the Inca "... maintain[ed] the purity of the domestic water supply by directing agricultural and urban stormwater discharges away from the open domestic water supply canals" (Wright, 2008, p. 87). Even though the Inca did not have the chemical treatments and methods of purifying water that exist today, the engineers saw the importance of properly, safely, reliably, and sustainably handling stormwater and runoff. The water systems of the Inca include canals, fountains, drainage systems, and extensive irrigation and were so well constructed that they still work today ("Machu Picchu and Inka Technology," 2007). Inca engineers also paid attention to water travel patterns, planning the order water would reach each fountain.

The work of the Inca is recognized due to the skill and knowledge used in constructing the fountains and canals of Machu Picchu with mainly stone and sometimes bronze as materials ("Machu Picchu and Inka Technology," 2007). The domestic water sources of the region include rainfall, tributary drainage basin, igneous bedrock, and extensive faulting, many of which are advantages exclusive to the region of Machu Picchu (Wright, Witt, \& Zegarra, 1997). The faults, or fractures between rock, take in precipitation and set up its release at a spring site, which allows for this source of water to reach the Inca people. In contrast to the development of Europe's dangerous and infectious water systems that caused diseases due to the inferior open-street sewer design, the Inca knew how to keep the water pure while optimizing its use ("Machu Picchu and Inka Technology," 2007). The Inca bathed separately from the fountains in "bathing rooms" with their drains (Brown, 2001). The stone conduits were set up in such a way as to prevent cross-contamination that flowed past fountains from their basins ("Machu Picchu and Inka Technology," 2007).

The Inca used consistent building design standards that adapted to diverse environments and took great care to incorporate adequate foundation drainage that still exists today four centuries later (Wright, 2008). The Inca worked throughout the Peruvian regions of Machu Picchu, Tipón, and Moray. Each had different water distribution priorities and needs: Machu Picchu needed to supply water to the emperor and the people, Tipón also had to serve nobility as well as have an irrigation system, and Moray had a focus on agriculture. The difference in land and climate between the three areas forced the Inca to adjust to different conditions with their versatile engineering and the few resources that they had available to them.

Machu Picchu's main source of water is a natural mountainside spring with a yield enhanced by an engineered stone collection system that allows water to percolate through its wall and flow into the receiving channel (Wright, 2008). The spring directly feeds into a canal designed for efficient water release 
and control to optimize the amount of water that makes it through the journey. Clay seals were also reliable and minimized maintenance requirements due to a lack of rust problems. The terraces support the canals to reduce any sliding and settlement that may occur from the weight of the stone. The canals lead to the 16 fountains on Machu Picchu that the Inca arranged in a hierarchical way to fit their cultural purposes. Each fountain has a stone conduit that delivers water at its head, an optimally sized drain outlet, and a well-designed spout to fill the common Inca water jug, or aryballos. The fountains contained basins with a corner that empties and carries the water towards the exterior drainage channel. The Inca's design followed the Venturi principle which adjusts the width of the channel to the fountains to adjust water jet flow, which follows the equation, velocity $=$ discharge/area. Official laboratory testing of water to check for inorganics and dissolved metals from the Machu Picchu water distribution canals came back clean and up to modern standards (Wright, Wright, \& Zegarra, 2002).

Moray and Tipón used stone conduits as Machu Picchu did for water distribution (Wright, 2008). The stone conduits collect subsurface flow and make handling and distribution easier through their placement in the hillside. Moray faced a lot more variation than Machu Picchu when it came to the amount of available water each day and relied on springs, canals, reservoirs, and irrigation features as sources and distribution methods. Moray's Inca reservoirs gradually and plentifully released spring flows by storing water when needed. Tipón was an estate for Inca nobility, like Machu Picchu, that required irrigation, like Moray. Its groundwater supply came from a high-yielding spring that issued from the base of a volcanicrock.

\section{f. Drainage and Runoff at Machu Picchu}

Although all three of these locations thrived off of similar, or the same, engineering principles, most current knowledge of Inca engineering is from Machu Picchu. Drainage and runoff are two aspects of Inca engineering which are of great importance and relevance to current water systems. The Inca built a separate canal to carry fountain overflow to the agricultural terraces or fall onto fountain-adjacent stairways for disposal (Wright, Kelly, \& Zegarra, 1997). Any drainage from agricultural terraces went to additional fountains, which is the only example of water reuse on all of Machu Picchu.

The surface drainage system directed agricultural and urban stormwater runoff away from the water supply canal (Brown, 2001). Thatched roofs on the Inca domiciles guided the water off of the roof and prevented leakages. $60 \%$ of the water yield from urban areas would be surface flow. The overflowing canal for irrigation and an overflow outlet by one of the fountains controlled part of the flooding. The granite rock stairways that lay adjacent to the fountains had integrated parallel storm runoff channels that convey water down the steep slopes of the mountain (Wright, 2013). Agricultural terraces were held in place by stone retaining walls, which protected the agricultural sector from erosion (Brown, 2001).

The Inca also had subsurface drainage in mind when constructing the terraces by layering each terrace with a layer of stones at the bottom and gravel, sandy material, and topsoil on top (Brown, 2001). The subsurface layer of rocks helped the runoff water remain off of the surface and not pick up contaminants by spreading across other areas. Gravity uses the slopes of the terraces to direct the water canals toward a system of stairway-integrated drainage channels and other structures that take runoff and drainage water to the main drain in the center plaza of Machu Picchu. The final discharge of drainage after traveling through the main drain is into the main Plaza of the nearby villages for infiltration (Wright, 2013). To control more runoff, the engineers built a north-south interceptor drain (Brown, 2001).

The drainage outlets of Machu Picchu are a notable aspect of engineering and have ideal spacing and capacity to deal with runoff (Wright, 2013). There are around 130 of these outlets placed in walls and other structures, drainage channels in stairways, walkways, and building interiors to bring runoff to the main drain (Brown, 2001). Drip channels on roofs help with runoff control by directing water to the peripheral surface drains where it then reaches the Plaza with the other drained water (Wright, 2013). The Inca formed their layered terraces of topsoil, sand, and gravel above stone and rockfill layers to support all of the canals and drains as well as prevent water from traveling as easily on surfaces where it can absorb contaminants.

\section{Research Applications}

\section{a. The Applicability of Inca Engineering Today}

Although dwellers abandoned Machu Picchu in 1572, the longevity of Inca engineering through the treatment of runoff and stormwater and the use of natural materials for water transport that defends against contaminants ("Machu Picchu and Inka Technology," 2007). Using these old ideas to shape modern solutions will promote water conservation, defend against contamination, effectively route runoff, floodwater, and stormwater, and enhance stewardship of the environment. Nevertheless, as with most things, there are some shortcomings between past and present. Machu Picchu had a large agricultural advantage over many places today in that it received enough rainfall and did not need an irrigation system. They also did not have to deal with the urban sprawl and industrialization of the present, which meant less of a population to provide for and less opportunity for major contamination issues. Regardless of these differences, the focus on maintaining a healthy environment and population of the Inca is comparable to the current drive towards sustainability.

\section{b. Proposed Modern-Day Solutions}


Even though not much visible action has taken place towards more sustainable water infrastructure today, various institutions and organizations have proposed and looked into more sustainable options. The "U.S. Water Supply and Distribution Factsheet" recognizes the types of changes that are necessary for achieving sustainability, including the rehabilitation, repair, and replacement of water distribution infrastructure, reducing chemical use for treatment and sludge, directly protecting source water instead of treating it later, and using onsite-energy sources, such as solar and wind power, for lower water consumption rates (Center for Sustainable Systems, 2020). The proposals from Water Resources Engineering include increasing reservoir capacities, extracting more water from rivers or groundwater, altering system operating rules, transferring water between basins, and desalinating ocean water (Mays, 2011). Other options that Mays discussed include controlling soil subsidence, protecting the quality of groundwater, reducing leakages, aggressively and innovatively reusing wastewater, educating others on water sustainability through programs, improving economic tools, harvesting rainwater, and improving energy efficiency in pumping systems, pumps, and motors. The "U.S. Water Supply and Distribution Factsheet" also proposes solutions, such as building technology for leak detection and metering and forming water audit programs and public education (Center for Sustainable Systems, 2020). Many of these options would require critical organization or would be very expensive to execute, but protecting water quality, harvesting stormwater, and providing education on water sustainability are all instances of plausible proposed solutions where the priorities and materials of Inca engineering can be useful (Mays, 2011).

\section{c. The Deficiencies of Current Research}

Current research seems to lack information that would have been useful for analysis, such as more details on the Inca's use of runoff, stormwater, and drainage. The source from the British Columbia Water \& Waste Association brought up the process of stormwater collection and its release back out into the environment with no treatment but does not suggest any potential solutions to this (British Columbia Water \& Waste Association). None of the sources on the Inca talked about the

\section{REFERENCES}

[1] British Columbia Water \& Waste Association. (n.d.). How Do Our Water Systems Work? Value of Water Canada. Retrieved 2020, from http://www.valueofwater.ca/water-facts/how-do-our-water-systems-work/

[2] Brown, J. L. (2001, January). Rediscovering the Lost City. Civil Engineering, 34-39.

[3] Center for Sustainable Systems, University of Michigan. (2020). U.S. Water

Supply and Distribution Factsheet.[6] Puttaswamaiah, S. (2005). Introduction. DRINKING WATER SUPPLY: http://css.umich.edu/sites/default/files/US\%20Water\%20Supply\%20and\%20DEnvironmental Problems, Causes, Impacts and Remedies - Experiences from istribution_CSS05-17_e2020.pdf

[4] Machu Picchu and Inka Technology. (2007, July 8). Web Archive. Karnataka (pp. 1-26). Gujarat Institute of Development Research. http://www.isec.ac.in/Drinking\%20Water\%20Supply.PDF

https://web.archive.org/web/20070310192723/http://carbon.cudenv er.edu/stc-link/machupicchu/inka/water.htm rate and amount of water used daily by the empire, which might be insufficiently known.

Because of the major differences between current society and society at the time of the Inca, not everything applies flawlessly. Open stone canals and fountains are impossible solutions for diminishing water contamination because of complications like air pollution, climate differences, and the variety of terrain across the world. Many different water purification methods exist today that did not in the 13th century. The uses of water have changed drastically with a better understanding of hygiene, electricity generation, the use of water as a power source, and different methods of irrigation.

\section{d. Conclusion: The Next Steps Towards Water Sustainability}

Current research agrees that the goal of sustainable water is important, but disagrees in terms of what the primary focus should be in working towards this goal. Some believe that the issue lies in the disorganization of maintenance and testing or in the materials and ways in which water distribution occurs, while others believe that harvesting stormwater and taking care of runoff is most important and plausible. Institutions should begin to restructure their operations with a pinpointed goal of what would help their communities achieve sustainability, whether that is in the form of sustainability awareness and education, research contributions, forming consistent maintenance schedules, etc. Professionals should conduct more research to create a better water collection system for stormwater and runoff and could consist of testing both Inca and modern practices. A better collection system would keep the environment safe in terms of pollutant spread and potable water access and optimize the amount of water that people have access to by limiting the amount of contaminated water released into the environment and harvesting and treating any for regular use. The Inca stone canals and thatched roofs have the potential to assist in developing distribution networks with longer and more convenient lifespans to diminish maintenance and replacement needs (Brown, 2001). With all of the current research done on Inca engineering and today's water issues, the straightforward, but important, takeaway is that time, effort, attention, and collaboration are necessary for gaining a more promising tomorrow.

[5] Mays, L. W. (2011). Water Resources Engineering (2nd ed.). John Wiley \& Sons, Inc. https://books.google.com/books?hl=en\&lr=\&id=Nh8Y3vIjXK8C \&oi=fnd \&pg=PR5\&dq=water+engineering\&ots=xfxDnje_Ur\&sig

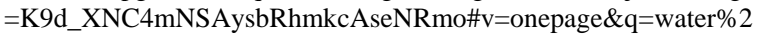
0engineering $\& \mathrm{f}=$ false 
[8] Wright, K. R., Witt, G. D., \& Zegarra, A. V. (1997, July-August). Hydrogeology and Paleohydrology of Ancient Machu Picchu. GROUND WATER, 35(4).

[9] Wright, K. R., Kelly, J. M., \& Zegarra, A. V. (1997, October). Machu Picchu: Ancient Hydraulic Engineering. Journal of Hydraulic Engineering, $123(10), 838-843$.

[10] Wright, K. R., Wright, R. M., \& Zegarra, A. V. (2002). Lost Inca Trail: Prehistoric Civil Engineering. American Civil Engineering History: The Pioneering Years, 397-438.

[11] Wright, K. R. (2008). A True Test of Sustainability. Water $\begin{array}{llll}\text { Environment } \quad \& \quad \text { Technology, 78-87. } & \text {. }\end{array}$ https://www.sewerhistory.org/images/w/wsa/WET_Feature1Wrigh t_Sept08_wsa01.pdf

[12] Wright, K. (2010, January 1). A Marvel of Inca Engineering.
Public

Broadcasting

Service. https://www.pbs.org/wgbh/nova/article/wright-inca-engineering/

[13] Wright, K. R. (2013, May). Inca Foundations, Site Preparation, and Drainage at Machu Picchu. Practice Periodical on Structural Design and Construction, 18(2), 131-142. 10.1061/(ASCE)SC.5576.0000146

\section{AUTHOR}

First Author - Catherine Ruiz, student at the Academy for Science and Design - catherine.ruiz@asdnh.org 